\title{
Enhancing task solving efficiency by the stimulation of crystallized and/or fluid intelligence using environmental factors
}

\author{
Sorin PENTA ${ }^{1}$, Mirella ANGHEL ${ }^{2}$, Cristina TALPOS-NICULESCU ${ }^{2}$, Veronica ARGESANU ${ }^{3}$, \\ Ligia Adriana STANCA MUNTIANU ${ }^{4}$ \\ ${ }^{1} 2^{\text {nd }}$ Department Ergonomy and Scientific Methodology Research, „Carol Davila“ University of \\ Medicine and Pharmacy, Bucharest \\ ${ }^{2} 1^{\text {st }}$ Department Oral Diagnosis and Ergonomics, „Victor Babes“ University of Medicine and Pharmacy, \\ Timisoara \\ ${ }^{3}$ UPT Mechanics Department, Bucharest \\ ${ }^{4} 1^{\text {st }}$ Department Removable Denture, „Carol Davila“ University of Medicine and Pharmacy, Bucharest
}

\begin{abstract}
Aim. The study analyzes the influence of environmental factors on cristalyzed and/or fluid intelligence stimulation and theyr apport in increasing efficiency.

Material and method. Two groups of students were stimulated by environmental factors aiming to temporarily increase fluid intelligence, or both cristalyzed and fluid intelligence. The effects were evaluated using a special designed test.

Results and conclusion. For a task that requires attention, being under time pressure, fluid intelligence stimulation is crucial, improving the results by $21.88 \%$. The benefit of supplementary stimulating crystallized intelligence, brought only an increase 10 times weaker, of $2.03 \%$, up to $23.91 \%$ in performance improvement. This advantage was obtained by consuming a double time versus the group receiving only stimulated fluid intelligence.

We managed to reduce by over $20 \%$ the errors by stimulating fluid intelligence by environmental factors.
\end{abstract}

Keywords: fluid intelligence, crystallized intelligence, efficiency

\section{INTRODUCTION}

We started this study because an observation made during a research on fatigue. Some colleagues began working at the patient with high initial physical and especially mental fatigue levels, which of course affects work performance. Under these circumstances, we studied the possibilities of psychic level augmentation and removal of mental fatigue in order to increase work efficiency. Our attention was drawn to a new scientific branch of cognitive ergonomics (1), neuroergonomics (2) dealing with the interaction between the human mind and work process and human performance (3). A related field (with much discussed ethical aspects) cognitive enhancement, has exactly the activity ob- 
ject needed in study. Much blamed (4) for the dream to provide "intelligence in a pill", it also offers other methods, without risk, to increase cognitive capacities.

One of these safe methods is the use of environmental factors, which can stimulate the fluid intelligence (dealing with reasoning, and new problem solving).

\section{MATERIALS AND METHOD}

Among the environmental factors that influence the fluid intelligence, one is creating an environment of "friendly competition" (5). The competition actually stimulates creativity and "friendship" is intended to combat the negative aspects of competition.

We wanted to investigate the quantum of additional benefit brought by the supplementary stimulation of the crystallized intelligence (based on learning and previous experience). For this purpose we selected two groups of students who were motivated differently. We designed a questionnaire in which students had to count each of the letters: $b, d, p$ and $q$ present in each box of a table with 36 boxes, and find out how many times each letter repeats (Fig. 1).

$$
\mathrm{B}=\text { ?; } \mathrm{D}=\text { ? ; } \mathrm{P}=\text { ? ; } \mathrm{Q}=\text { ? }
$$

\begin{tabular}{|c|c|c|c|c|c|}
\hline b & d & p & q & d & q \\
\hline d & p & q & d & b & p \\
\hline d & q & p & d & q & p \\
\hline b & p & q & b & d & b \\
\hline q & d & q & b & p & p \\
\hline q & p & b & p & p & d \\
\hline
\end{tabular}

\section{FIGURE 1}

We asked for the prior informed consent of all participating students. To increase the crystallized intelligence we used as method a discussion on a subject of immediate and intense interest for the students: the next exam. All the students were very attentive and active.

A. The first group was composed of 26 students. The experimental protocol was as follows, for the group to which stimulated both the fluid and crystallized intelligence.

a. We described this test to the students.

b. We have provided a set of tests similar to those used in the real test, but with dif- ferent frequency and positioning of the four letters, so that students can complete in order to familiarize them with the type of test. We offered for this test about 2 minutes (afterwards letting the tests to the students).

c. We had discussion on the themes for the next exam for approximately 10 minutes

d. We administered the first test, for which we offered $1 \frac{1}{2}$ minutes to solve.

e. We presented the perspicacity problem, whose solution required approx. 9 minutes.

f. We administered the second test, for which we offered also $1 \frac{1}{2}$ minutes to solve.

B. The second group was composed of 23 students. The experimental protocol was as the same, for the group to which only stimulated fluid intelligence, excepting the point $c$ which was omitted. From point $d$ on the test was similar.

1 . The results of the group with stimulation fluid intelligence tests 1 and 2 are presented in Tables 1 and 2 and in Chart 1.

\section{TABLE 1}

\begin{tabular}{|c|c|c|c|c|}
\hline 1 & NAME, GR. & TEST 1 & TEST 2 & RESULTS \\
\hline 2 & DA 10 & 0 & 1 & DECREASE \\
\hline 3 & DCE 10 & 0 & 0 & THE SAME \\
\hline 4 & DM 10 & 0 & 0 & THE SAME \\
\hline 5 & CC 11 & 0 & 0 & THE SAME \\
\hline 6 & VR 12 & 0 & 1 & DECREASE \\
\hline 7 & CA 13 & 0 & 2 & DECREASE \\
\hline 8 & BB 14 & 0 & 2 & DECREASE \\
\hline 9 & BA 11 & 1 & 1 & THE SAME \\
\hline 10 & CA 11 & 1 & 0 & INCREASE \\
\hline 11 & DA 11 & 1 & 3 & DECREASE \\
\hline 12 & CA 11 & 1 & 1 & THE SAME \\
\hline 13 & EJ 12 & 1 & 2 & DECREASE \\
\hline 14 & DDC 10 & 2 & 0 & INCREASE \\
\hline 15 & C C 12 & 2 & 2 & THE SAME \\
\hline 16 & GS 12 & 2 & 0 & INCREASE \\
\hline 17 & MCC 14 & 2 & 4 & DECREAS \\
\hline 18 & BM 14 & 2 & 0 & INCREASE \\
\hline 19 & TO 12 & 3 & 0 & INCREASE \\
\hline 20 & $A C 13$ & 3 & 2 & INCREASE \\
\hline 21 & Al 11 & 4 & 4 & THE SAME \\
\hline 22 & DAE 11 & 4 & 4 & THE SAME \\
\hline 23 & GM 12 & 4 & 1 & INCREASE \\
\hline 24 & AR 13 & 5 & 0 & INCREASE \\
\hline 25 & D D 13 & 5 & 2 & INCREASE \\
\hline 26 & GI 10 & 7 & 1 & INCREASE \\
\hline 27 & $\mathrm{Cl} 11$ & 7 & 2 & INCREASE \\
\hline & TOTAL ERRORS & 57 & 35 & \\
\hline
\end{tabular}




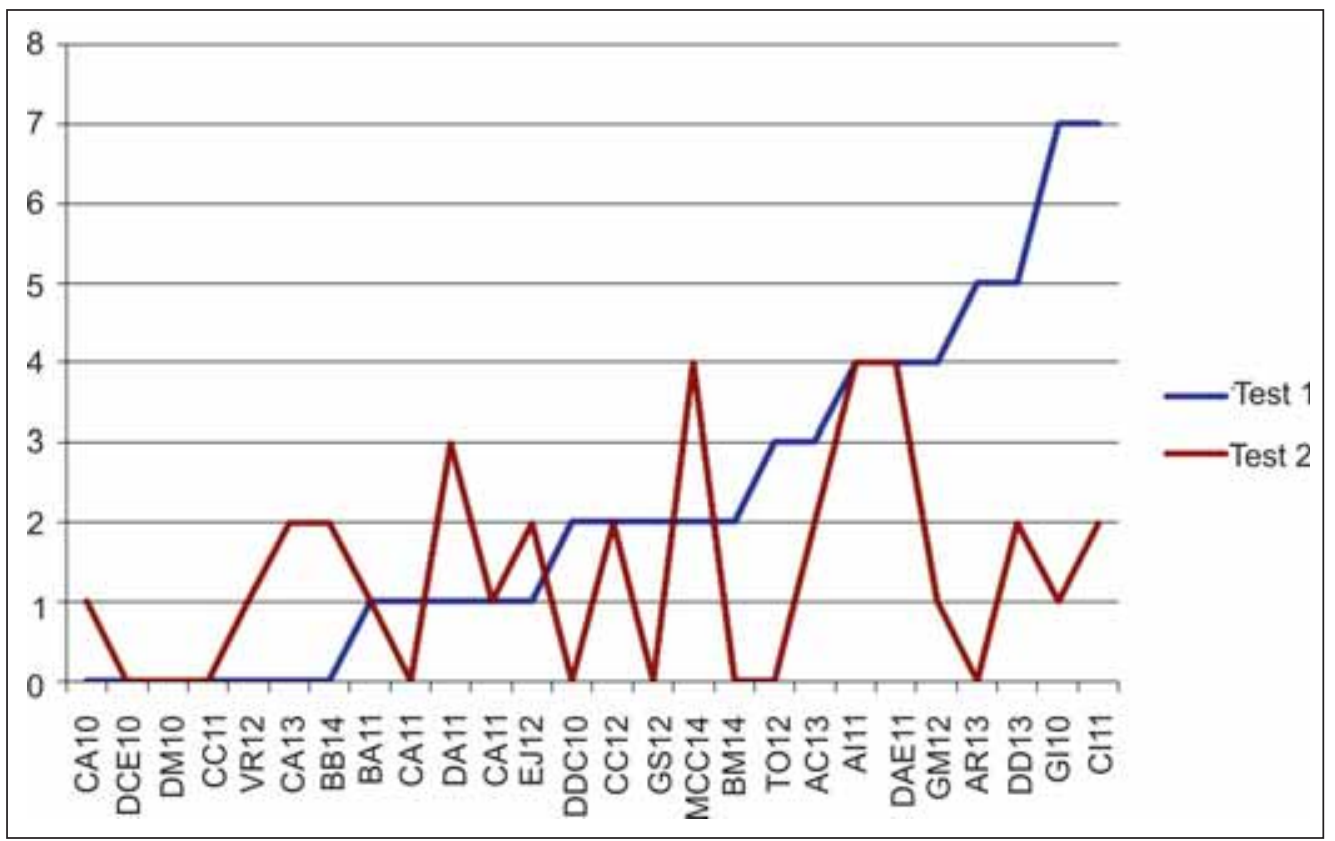

CHART 1. The number of errors in the group with the fluid intelligence stimulation-tests 1 and 2

\section{TABLE 2}

\begin{tabular}{|c|c|c|c|c|c|}
\hline \multicolumn{3}{|c|}{ TEST 1 FLUID INT. } & \multicolumn{3}{c|}{ TEST 2 F FLUID INT. } \\
\hline $\begin{array}{c}\text { Nr. mistaken } \\
\text { points }\end{array}$ & $\begin{array}{c}\text { Nr. } \\
\text { students }\end{array}$ & $\begin{array}{c}\text { Percentage } \\
\text { test 1 }\end{array}$ & $\begin{array}{c}\text { Nr. mistaken } \\
\text { points }\end{array}$ & $\begin{array}{c}\text { Nr. } \\
\text { students }\end{array}$ & $\begin{array}{c}\text { Percentage } \\
\text { test 2 }\end{array}$ \\
\hline 0 & 7 & $27 \%$ & 0 & 9 & $35 \%$ \\
\hline 1 & 5 & $19 \%$ & 1 & 7 & $23 \%$ \\
\hline 2 & 5 & $19 \%$ & 2 & 6 & $27 \%$ \\
\hline 3 & 3 & $8 \%$ & 3 & 1 & $4 \%$ \\
\hline 4 & 3 & $11 \%$ & 4 & 3 & $11 \%$ \\
\hline 5 & 2 & $8 \%$ & Results of the group with fluid \\
\hline 7 & 2 & $8 \%$ & \multicolumn{5}{|l}{} \\
\hline
\end{tabular}

Students who correctly solved the first test were $7(27 \%)$, and those who correctly solved the second test were 9 (35\%), an increase of $7 \%$

The results of the group "with both the crystallized intelligence and fluid intelligence stimulation - tests 1 and 2 are shown in Tables 3 and 4 , as well as in the Chart 2.

TABLE 3

\begin{tabular}{|l|c|c|c|c|}
\hline & NUME GR. & TEST 1 & TEST 2 & RESULTS \\
\hline 1 & RAI 25 & 0 & 1 & DECREASE \\
\hline 2 & TFA 25 & 0 & 0 & THE SAME \\
\hline 3 & SCM 28 & 0 & 0 & THE SAME \\
\hline 4 & TG 28 & 0 & 0 & THE SAME \\
\hline 5 & SR 29 & 0 & 0 & THE SAME \\
\hline 6 & SV 29 & 0 & 0 & THE SAME \\
\hline 7 & TIA 29 & 0 & 1 & DECREASE \\
\hline 8 & VAE 30 & 0 & 4 & DECREASE \\
\hline 9 & RRA 25 & 1 & 0 & INCREASE \\
\hline 10 & FG 30 & 1 & 0 & INCREASE \\
\hline 11 & VII 30 & 1 & 0 & INCREASE \\
\hline 12 & ZB 30 & 1 & 2 & DECREASE \\
\hline
\end{tabular}

\begin{tabular}{|l|c|c|c|c|}
\hline & NUME GR. & TEST 1 & TEST 2 & RESULTS \\
\hline 13 & RCM 25 & 2 & 0 & INCREASE \\
\hline 14 & SC 25 & 2 & 4 & DECREASE \\
\hline 15 & CD 28 & 2 & 1 & INCREASE \\
\hline 16 & MAS 27 & 3 & 2 & INCREASE \\
\hline 17 & MIA 28 & 3 & 2 & INCREASE \\
\hline 18 & SM 28 & 3 & 1 & INCREASE \\
\hline 19 & PI 29 & 3 & 0 & INCREASE \\
\hline 20 & SI 28 & 4 & 2 & INCREASE \\
\hline 21 & TIM 28 & 4 & 2 & INCREASE \\
\hline 22 & VB 30 & 4 & 2 & INCREASE \\
\hline 23 & UDR 29 & 5 & 1 & INCREASE \\
\hline Total errors & & 39 & 35 & \\
\hline
\end{tabular}




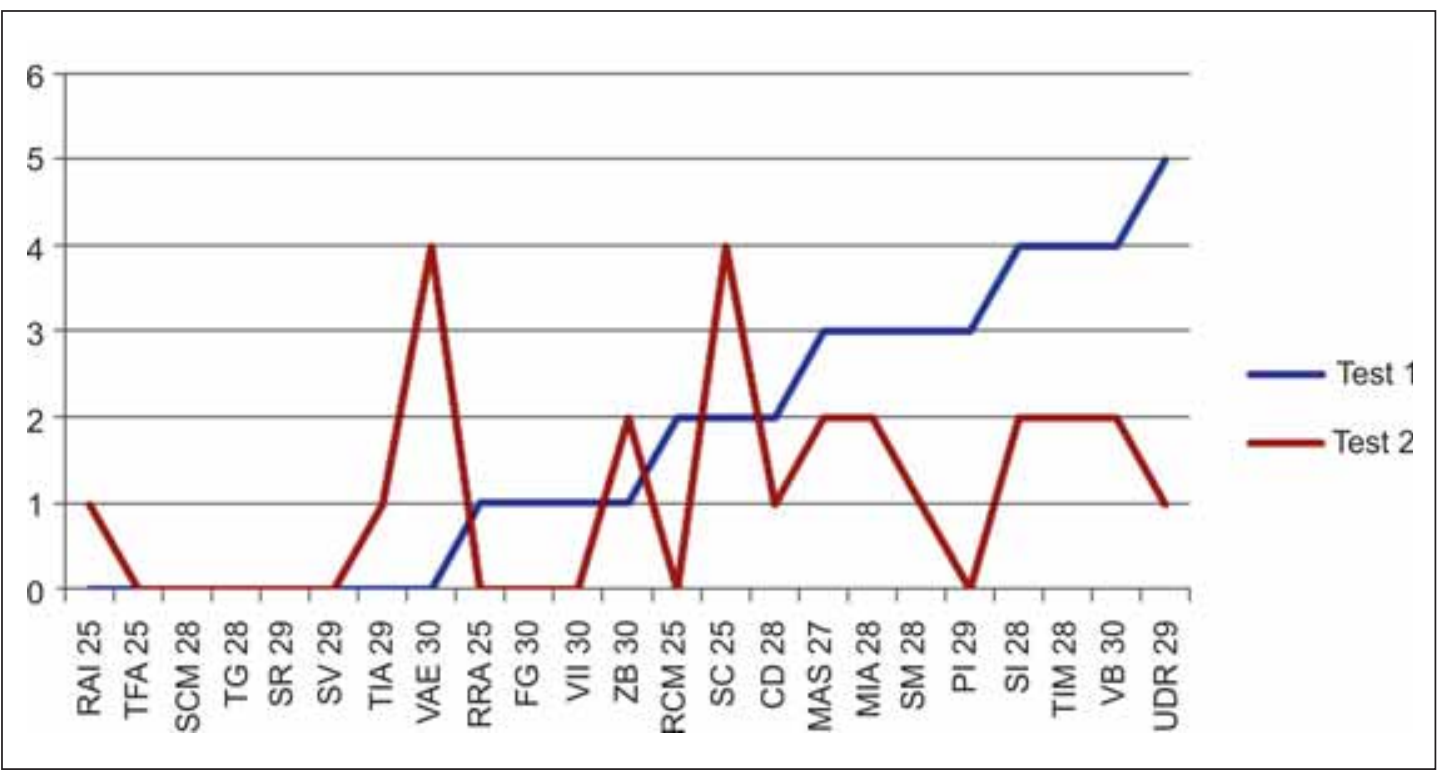

CHART 2. The number of errors - group with both the crystallized intelligence and fluid intelligence stimulation - tests 1 and 2

TABLE 4

\begin{tabular}{|c|c|c|c|c|c|}
\hline \multicolumn{7}{|c|}{$\begin{array}{l}\text { TEST 1 C+F } \\
\begin{array}{c}\text { Nr. mistaken } \\
\text { points }\end{array}\end{array}$} & $\begin{array}{c}\text { Nr. } \\
\text { students }\end{array}$ & $\begin{array}{c}\text { Percentage } \\
\text { test 1 }\end{array}$ & $\begin{array}{c}\text { Nr. mistaken } \\
\text { points }\end{array}$ & Nr. students & $\begin{array}{c}\text { Percentage } \\
\text { test 2 }\end{array}$ \\
\hline 0 & 8 & $35 \%$ & 10 & 0 & $42 \%$ \\
\hline 1 & 4 & $18 \%$ & 5 & 1 & $21 \%$ \\
\hline 2 & 3 & $13 \%$ & 6 & 2 & $25 \%$ \\
\hline 3 & 4 & $17 \%$ & 0 & 3 & $0 \%$ \\
\hline 4 & 3 & $13 \%$ & 2 & 4 & $8 \%$ \\
\hline 5 & 1 & $4 \%$ & 0 & 5 & $4 \%$ \\
\hline & 39 & & 25 & & \\
\hline
\end{tabular}

The students who correctly solved the first test, $8,35 \%$, as in the case of the first group $(1 / 3)$. The second test correctly solved 10 students, $42 \%$, an increase of 7 .

\section{DISCUSSION OF RESULTS}

The essential is the number of points each mesurement differs from the correct answer. Total errors (in points of difference) for each group and for each of the two tests, are presented in Charts 3 and 4.

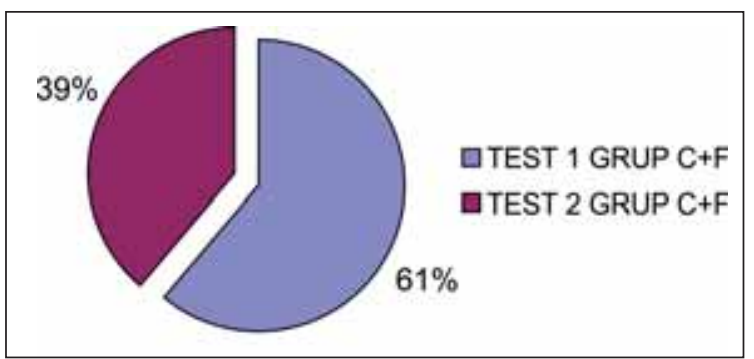

CHART 3. Number total of errors - group with crystallized + fluid intelligence stimulation

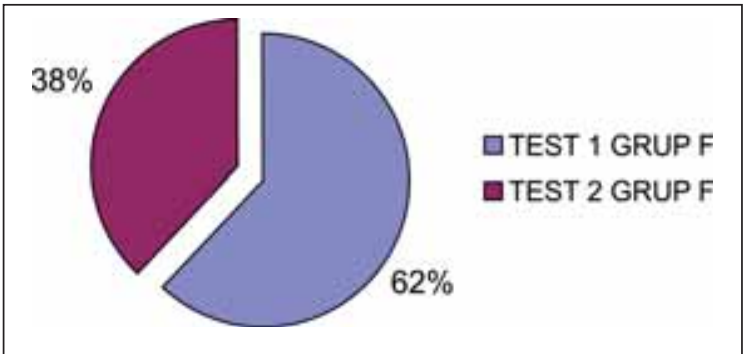

CHART 4. Number total of errors - group with fluid intelligence stimulation

In test 2 to for the group with stimulation fluid intelligence were wrong in just 35 points total to 57 in the first test, the error is reduced with 22 points, in the group with stimulation of fluid and crystallized intelligence, were wrong in the second test only 25 points total to 39 in the first test, the error reduction with 14 points $(21.88 \%$ from total errors of this group). 


\section{CONCLUSIONS}

Stimulation of the two types of intelligence is a proven fact in psychological research. The factors involved in the two processes are different.

Our results indicate that for a task that requires attention, being under time pressure, fluid intelligence stimulation is crucial, improving the results by $\mathrm{n} 21.88 \%$. The benefit of supplementary stimulating crystallized intelligence, one that is based on prior learning and experiences brought only an increase 10 times weaker $2.03 \%$, up to $23.91 \%$ in performance improvement. This advantage is obtained by consuming a double time versus the group receiving only stimulated fluid intelligence.

We managed to reduce by over $20 \%$ the errors by stimulating fluid intelligence by environmental factors.

\section{REFERENCES}

1. Hollnagel E. - Cognitive ergonomics: it's all in the mind. Ergonomics. Volume 40, Issue 10, 1997 pages 1170-1182

2. Sarter N., Sarter M. Neuroergonomics: Opportunities and challenges of merging cognitive neuroscience with cognitive ergonomics, Theoretical Issues in Ergonomics Science. Volume 4, Issue 1-2, 2003, pages $142-150$
3. Parasuraman R., Rizzo M. Neuroergonomics: The Brain at Work. Oxford University Press 2007 p. 10

4. Greely H., Sahakian B., Harris J., Kessler R.C., Gazzaniga M., Campbell P., Farah M.J. Towards responsible use of cognitiveenhancing drugs by the healthy nature. 2008 Dec 11; 456(7223):702-5. doi: $10.1038 / 456702 a$
5. Burguillo J.C. Using game theory and Competition-based Learning to stimulate student motivation and performance. Computers \& Education. Volume 55, Issue 2, September 2010, Pages 566-575

\section{Vizitați site-ul}

SOCIETĂȚII ACADEMICE DE MEdicinĂ A FAMILIEI www.samf.ro 